\title{
Xilitol: Edulcorante com efeitos benéficos para a saúde humana
}

\author{
Solange Inês Mussatto, Inês Conceição Roberto*
}

Departamento de Biotecnologia - Faculdade de Engenharia Química de Lorena - Lorena, São Paulo

*Correspondência:

I. C. Roberto

Faculdade de Engenharia Química de Lorena

Departamento de Biotecnologia Rodovia Itajubá-Lorena, Km 74,5 CEP: 12608-970 - Lorena/SP - Brasil E-mail: ines@debiq.faenquil.br

\begin{abstract}
Ao empregar adoçantes na produção de bebidas e alimentos, as indústrias atualmente levam em conta a quantidade de calorias do edulcorante, a possibilidade de seu uso em dietas para redução ou controle de peso e o grau de semelhança entre o seu sabor e o do açúcar. Nesse sentido, um produto que vem atraindo a atenção dos fabricantes de bebidas e alimentos é o xilitol, adoçante que se destaca das demais substâncias do gênero, não só pelo fato de poder ser obtido por via biotecnológica, mas também por possuir importantes propriedades físico-químicas e fisiológicas. Graças a essas propriedades, oxilitol tem um grande potencial de aplicação nas áreas odontológica e médica, tendo-se mostrado eficaz no combate às cáries dentárias e no tratamento de outros males como diabetes, desordem no metabolismo de lipídeos e lesões renais e parenterais. Além disso, o xilitol previne infecções pulmonares, otite e osteoporose. Por todas essas razões, a incorporação do xilitol em dietas alimentares representa beneficio tanto para os que necessitam de uma dieta controlada quanto para aqueles que, embora não tendo distúrbios metabólicos, preocupam-se com a saúde e com o bem-estar fisico.
\end{abstract}

\author{
Unitermos: \\ - Xilitol \\ - Cáries dentárias \\ - Diabetes \\ - Otite \\ - Osteoporose \\ - Infecções respiratórias
}

\section{INTRODUÇÃO}

Em vista do crescente número de pessoas que apresentam algum tipo de distúrbio metabólico e necessitam, por isso, diminuir ou mesmo cessar seu consumo de açúcar, vários centros de pesquisa nacionais e estrangeiros têm tentado encontrar um substituto do açúcar que seja, ao mesmo tempo, nutritivo e benéfico para a saúde, atuando na cura ou na prevenção de doenças.

O xilitol, poliálcool cuja fórmula molecular é $\mathrm{C}_{5} \mathrm{H}_{12} \mathrm{O}_{5}$ (1,2,3,4,5-pentaidroxipentano), é um composto que satisfaz essas exigências, pois, além de ser um adoçante perfeitamente capaz de substituir a sacarose, é tolerado por diabéticos e tem várias aplicações clínicas. De estrutura aberta, a molécula de xilitol possui cinco grupos hidroxila $(\mathrm{OH})$, cada um deles ligado a um átomo de carbono, razão pela qual esse composto é conhecido como poliidroxiálcool acíclico ou pentitol (Mäkinen, 2000).

Uma das vantagens do xilitol sobre a sacarose é que, em virtude de sua elevada estabilidade química e microbiológica, ele atua, mesmo em baixas concentrações, como conservante de produtos alimentícios, oferecendo resistência ao crescimento de microrganismos e prolongando a vida de prateleira desses produtos (Bar, 1991). Uma outra vantagem é que, devido à ausência de 
grupos aldeídicos ou cetônicos em sua molécula, o xilitol não participa de reações com aminoácidos, conhecidas como reações de "Maillard". Isto significa que ele não sofre reações de escurecimento não enzimático, que provocam diminuição do valor nutricional das proteínas. Dessa forma, recomenda-se sua utilização na manufatura de produtos nos quais as reações de Maillard são indesejáveis, tais como os alimentos infantis obtidos por secagem. Entretanto, em produtos de padaria, o uso exclusivo de xilitol oferece problemas, uma vez que as reações de escurecimento são responsáveis pela aparência e pelas características flavorizantes desses produtos (Manz et al., 1973). Em razão de seu elevado calor de solução endotérmico $(34,8 \mathrm{cal} / \mathrm{g})$, o xilitol produz um agradável efeito refrescante na boca, quando entra em contato com a saliva. Devido a essa propriedade organoléptica, o xilitol realça o efeito refrescante dos produtos com sabor de menta, tais como balas e gomas de mascar (Pepper, Olinger, 1988). As propriedades físico-químicas do xilitol estão apresentadas na Tabela I.

Sendo o xilitol uma substância atóxica, classificada pela Food and Drug Administration (FDA) como um aditivo do tipo GRAS (Generally Regarded as Safe), sua incorporação em alimentos é legalmente permitida. De acordo com a literatura, o xilitol é extremamente bem tolerado, quando ingerido em doses espaçadas de no máximo $20 \mathrm{~g}$ cada uma, e desde que a quantidade consumida por dia não ultrapasse $60 \mathrm{~g}$, já que a ingestão de doses mais elevadas produz efeito laxativo. Esse efeito é provavelmente levado em conta quando o xilitol é utilizado em alimentos normalmente ingeridos em grandes quantidades, como é o caso dos refrigerantes, por exemplo (Culbert et al., 1986). No entanto, a Organização Mundial da Saúde (OMS) não estabeleceu um limite para a ingestão diária aceitável deste edulcorante e a FDA indica que seu consumo é permitido na quantidade necessária para atingir o adoçamento desejado.

O uso de xilitol em produtos industrializados já foi aprovado em mais de quarenta países, e as indústrias que mais o utilizam são, pela ordem, a de alimentos, a de fármacos e a de cosméticos. Na Escandinávia e em outras partes da Europa, o xilitol vem sendo amplamente utilizado nesses três setores industriais há mais de 20 anos. No Brasil, as indústrias estão começando a incluir o xilitol na formulação de produtos, atraídas pelo seu efeito refrescante e, sobretudo, pela sua ação anticariogênica. Entre os produtos com xilitol que já se acham disponíveis no mercado brasileiro, enumeram-se, na área de comestíveis, as gomas de mascar, balas, confeitos, compotas, caramelos, chocolates, geléias, sobremesas e pudins, e na área de dentifrícios, os cremes dentais e as soluções para lavagem
TABELA I - Características e propriedades físico-químicas do xilitol (Hyvonen et al., 1982; Bar, 1991)

\begin{tabular}{|c|c|}
\hline Propriedades & Características ou Valores \\
\hline Fórmula empírica & $\mathrm{C}_{5} \mathrm{H}_{12} \mathrm{O}_{5}$ \\
\hline Massa molar & $152,15 \mathrm{~g} / \mathrm{mol}$ \\
\hline Aparência & Pó cristalino \\
\hline Cor & Branca \\
\hline Sabor & Doce \\
\hline Odor & Nenhum \\
\hline Ponto de Fusão & $92-96{ }^{\circ} \mathrm{C}$ \\
\hline Ponto de Ebulição & $216^{\circ} \mathrm{C}(1 \mathrm{~atm})$ \\
\hline $\begin{array}{l}\text { pH (solução aquosa } \\
\text { a } 10 \% \text { ) }\end{array}$ & $5-7$ \\
\hline $\begin{array}{l}\text { Densidade (solução } \\
\text { aquosa a } 10 \% \text { ) }\end{array}$ & $1,03 \mathrm{~g} / \mathrm{mL}$ \\
\hline $\begin{array}{l}\text { Solubilidade em } \\
\text { água a } 20^{\circ} \mathrm{C}\end{array}$ & $63 \mathrm{~g} / 100 \mathrm{~g}$ solução \\
\hline $\begin{array}{l}\text { Viscosidade (solução } \\
\text { aquosa a } 10 \% \text { ) }\end{array}$ & $1,23 \mathrm{cP}\left(\mathrm{a} 20^{\circ} \mathrm{C}\right)$ \\
\hline $\begin{array}{c}\text { Calor de Solução } \\
\text { (endotérmico) }\end{array}$ & $34,8 \mathrm{cal} / \mathrm{g}$ \\
\hline Valor Calórico & $2,4 \mathrm{kcal} / \mathrm{g}$ \\
\hline Índice de Refração $\left(25^{\circ} \mathrm{C}\right)$ & $\begin{array}{l}\text { 1,3471 (solução aquosa } \\
\text { a } 10 \% \text { ) }\end{array}$ \\
\hline Higroscopicidade & $\begin{array}{l}\text { Em elevada umidade } \\
\text { relativa, é mais } \\
\text { higroscópico que a } \\
\text { sacarose e menos } \\
\text { que o sorbitol }\end{array}$ \\
\hline Poder adoçante & $\begin{array}{l}\text { Similar ao da sacarose, } \\
\text { superior ao do sorbitol } \\
\text { e manitol }\end{array}$ \\
\hline Estabilidade & $\begin{array}{l}\text { Estável a } 120^{\circ} \mathrm{C} \\
\quad \text { (não carameliza) }\end{array}$ \\
\hline
\end{tabular}

bucal. De acordo com a Agência Nacional de Vigilância Sanitária (Anvisa), o xilitol é um aditivo alimentar do tipo umectante, que pode ser empregado em balas, confeitos, gomas de mascar e produtos do gênero, na quantidade necessária para se obter o efeito desejado ("quantum satis"), uma vez que este não afeta a identidade e a genuinidade dos alimentos (ANVISA, 2002a,b). Na indústria farmacêutica, o xilitol pode ser empregado como adoçante ou excipiente na formulação de xaropes, tônicos e vitaminas (Bar, 1991). Entretanto, como seu preço é relativamente alto (custo de produção cerca de 10 vezes superior ao da sacarose ou do sorbitol - Parajó et al., 1998a), ele é normalmente utilizado em combinação com outros polióis que servem como agente de corpo da mis- 
tura (Mäkinen et al., 1998). Vale a pena destacar que no ano de 2000/2001 o mercado de polióis atingiu um valor de vendas de 1,4 milhões de toneladas, com um faturamento da ordem de 1,3 bilhões de dólares. O xilitol foi responsável pela segunda maior parte deste mercado $(12 \%)$, perdendo apenas para o sorbitol (48\%). Devido ao fato de este mercado já se encontrar estabelecido e em crescimento constante, estima-se que nos próximos cinco anos a taxa de crescimento neste setor seja de 2 a $3 \%$ anualmente (Business Communications, 2002).

Recentes pesquisas com animais e humanos demonstram que o xilitol, além de poder ser utilizado como um ingrediente alimentar, possui várias aplicações clínicas, sendo indicado para tratar diabetes, desordem no metabolismo de lipídeos, e lesões renais e parenterais, bem como para prevenir otite, infecções pulmonares e osteoporose. Apesar de alguns desses estudos ainda estarem em andamento, os resultados até agora obtidos já permitem uma análise global dos benefícios da administração de xilitol para pacientes com diversos tipos de patologias. Essa análise é apresentada neste trabalho, que também discute as vantagens clínicas da incorporação do xilitol em dietas alimentares, assim como as possíveis vias de obtenção desse edulcorante.

\section{ANTICARIOGENICIDADE}

De uma forma geral, a saúde do organismo está diretamente ligada à saúde bucal, mantida principalmente pela boa higiene, pela redução da ingestão de açúcares ou ainda pelo uso de adoçantes não-cariogênicos.

A cárie é o resultado de um processo infeccioso desencadeado pelas bactérias presentes na placa dentária. As bactérias do gênero Streptococcus, encontradas na flora bucal, são altamente cariogênicas, uma vez que, em condições ácidas, produzem uma grande quantidade de ácido lático e sintetizam polissacarídeos extracelulares, que aumentam a adesão da placa bacteriana na superfície dos dentes (Kandelman, 1997). Quanto mais cedo essas colônias aparecerem nos dentes, e quanto maior for a sua quantidade na flora bucal, maior será o risco de desenvolvimento de cáries.

A anticariogenicidade, uma das propriedades mais relevantes do xilitol, é determinada principalmente pela sua não-fermentabilidade por bactérias do gênero Streptococcus, cuja proliferação na flora bucal torna-se então limitada. Com a redução da concentração de Streptococcus mutans, diminui a quantidade de polissacarídeos insolúveis e aumenta a de polissacarídeos solúveis, o que resulta em uma placa menos aderente e de fácil remoção pela escovação habitual dos dentes (König, 2000; Gales, Nguyen, 2000).
Estudos recentes sobre indivíduos que substituíram o açúcar por xilitol mostram que a salivação é estimulada pelo agradável sabor do adoçante e que, uma vez aumentada a quantidade de saliva, aumenta também a quantidade dos minerais nela presentes. Alguns desses minerais (em particular íons cálcio e fosfato) promovem a remineralização dos dentes e, conseqüentemente, a reversão das cáries em estágio inicial. Segundo Kandelman (1997), a lavagem bucal com solução de xilitol evita a queda do $\mathrm{pH}$ da superfície dos dentes (uma das causas do aparecimento de cáries), uma vez que, com o aumento do fluxo salivar, eleva-se o pH da placa, o qual neutraliza os ácidos produzidos por outros carboidratos fermentescíveis que tenham sido ingeridos. Com isso, elevam-se também os níveis de algumas enzimas, aumentando a capacidade tamponante e a atividade bacteriostática da saliva. Dessa forma, o ambiente bucal torna-se pouco favorável ao desenvolvimento das bactérias. A Figura 1 mostra um esquema do processo de remineralização dos dentes decorrente do consumo de xilitol.

Em comparação com outros edulcorantes, o xilitol acarreta maiores benefícios para a saúde bucal, prevenindo a incidência de cáries ou reduzindo a sua formação. Os efeitos da substituição da dieta usual de sacarose por xilitol foram testados em alguns voluntários na Finlândia, os quais, ao final de dois anos, apresentaram uma redução de $85 \%$ na incidência de cáries dentárias, o que comprova a anticariogenicidade do xilitol (Mäkinen et al., 1998). Em estudos posteriores, avaliou-se o efeito de gomas de mascar contendo xilitol ou sorbitol em pacientes pertencentes a uma população de alto risco de desenvolvimento de cáries. Essas pessoas consumiram de 3 a 5 unidades de gomas de mascar por dia, durante 40 meses. Os resultados mostraram que as gomas de mascar que continham xilitol foram capazes de reduzir em até $63 \%$ as cáries desses pacientes, enquanto as que continham sorbitol reduziram as cáries em apenas 30\% (Gales, Nguyen, 2000). Os efeitos do consumo diário de 5,2 $\mathrm{g}$ de estimulantes de saliva contendo xilitol ou eritritol sobre o controle da placa dentária e de Streptococcus mutans também foram objeto de um estudo recente, no qual ficou demonstrado que, nos consumidores de xilitol, o peso da placa total (coletada durante um período de 3 minutos em toda a superfície dos dentes) e a quantidade de Streptococcus mutans presente na placa e na saliva sofreram uma redução significativa, ao passo que nos consumidores de eritritol nenhum efeito foi observado (Mäkinen et al., 2001). Esses resultados sugerem que as substâncias salivantes contendo xilitol podem ser altamente efetivas na higienização oral e no combate aos microrganismos causadores de cáries.

Vale a pena ressaltar que a formação de cáries em 


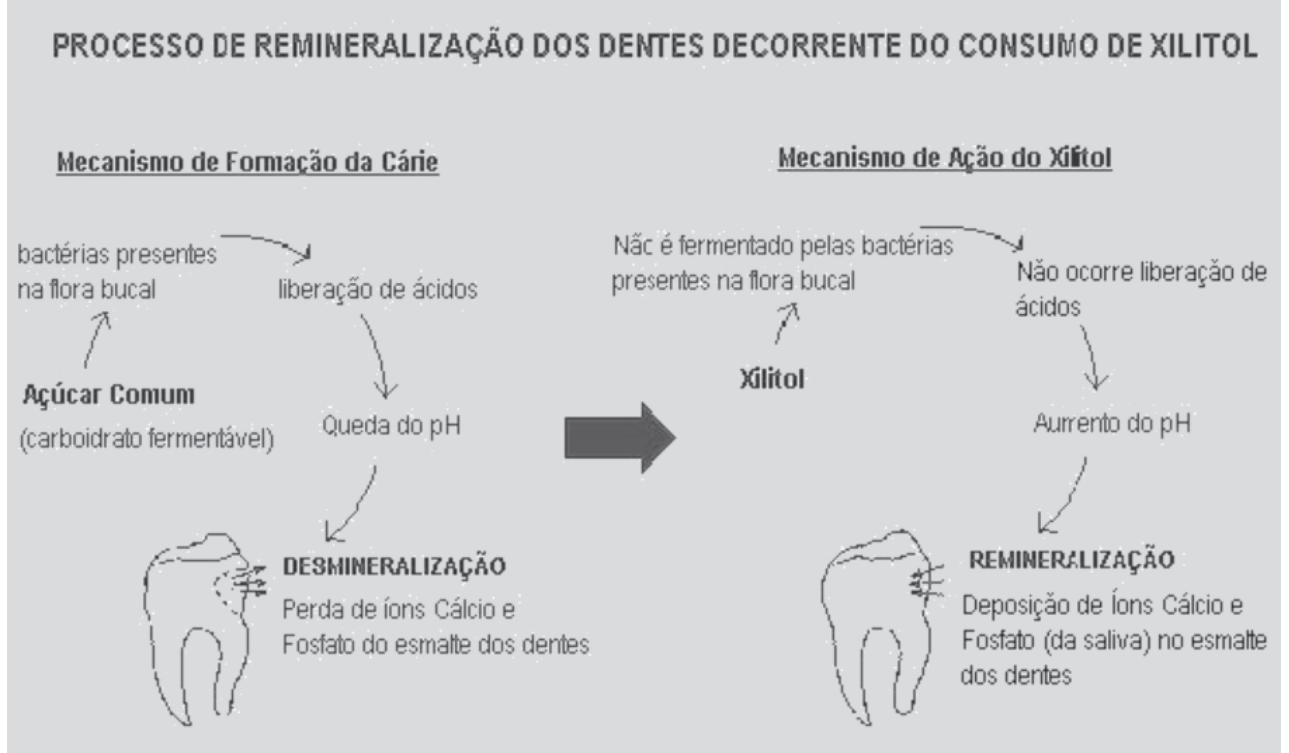

FIGURA 1 - Processo de remineralização dos dentes decorrente do consumo de xilitol.

crianças pode ser prevenida desde o nascimento. Durante a gravidez, as mães apresentam na saliva altos níveis da bactéria Streptococcus mutans, que é posteriormente transmitida aos filhos por meio da fala, do beijo, etc. A contaminação ocorre em crianças na faixa de 6 a 30 meses de idade, período em que surge a primeira dentição. Os bebês com menos de 6 meses não correm esse risco, porque a superfície dos dentes é requerida como habitat por essa bactéria. Söderling et al. (2000) fizeram um estudo com mães de bebês de 3 meses de idade, submetendo-as ao uso regular de gomas de mascar contendo xilitol. Após cerca de 2 anos, ao comparar essas crianças com outras da mesma idade, cujas mães não participaram desse estudo, esses autores notaram que os níveis de Streptococcus mutans nos filhos das usuárias de xilitol eram muito mais baixos, o que demonstra que o xilitol inibiu a transmissão da bactéria, reduzindo portanto o risco de formação de cáries. Isokangas et al. (2000) acompanharam esse mesmo grupo de crianças até a troca de sua dentição primária (por volta dos 5 anos de idade) e observaram que, mesmo com dentição secundária, essas crianças apresentaram níveis de $S$. mutans cerca de $70 \%$ mais baixos que os das crianças cujas mães não realizaram o tratamento.

Em resumo, o xilitol contribui para a saúde bucal de seis maneiras: (1) reduzindo a incidência de cáries; (2) estabilizando íons cálcio e fosfato na saliva e conseqüentemente remineralizando os dentes; (3) estabilizando as cáries já formadas; (4) reduzindo o crescimento de Streptococcus mutans e Lactobacillus na saliva; (5) estimulando a formação da saliva (sem aumentar a produção de ácidos na placa dentária); (6) controlando o pH da placa e a capacidade tamponante da saliva, após o consumo de sacarose (Kandelman, 1997; Mäkinen, 2000).

\section{DIABETES}

Em indivíduos com diabetes, ou seja, com deficiência no metabolismo de glicídeos, é de suma importância o controle da taxa de glicose no sangue, para evitar problemas como hiperglicemia, distúrbios no metabolismo de lipídeos e ainda sintomas como sede e fome exageradas. Ao contrário dos açúcares convencionais, o xilitol independe de insulina para ser metabolizado pelo organismo, sendo, por isso, bem tolerado pelas pessoas portadoras de Diabetes mellitus Tipo I ou Tipo II (Manz et al., 1973; Pepper, Olinger, 1988; Bar, 1991). De fato, nenhuma das duas principais vias de absorção do xilitol (fígado e flora intestinal) é mediada pela insulina. Embora o xilitol possa penetrar em quase todas as células do organismo, as do fígado são especialmente permeáveis e contêm uma enorme quantidade de enzimas capazes de rapidamente metabolizá-lo e transformá-lo em energia. A absorção pelo intestino é, ao contrário, consideravelmente lenta. Toda a D-glicose proveniente do metabolismo do xilitol é primeiro estocada como glicogênio no fígado e depois liberada gradualmente. Desse modo, sua concentração no sangue não sofre as mudanças bruscas causadas pela sacarose e pela glicose, o que faz do xilitol um adoçante apropriado para diabéticos (Ylikahri, 1979). De acordo com Ylikahri (1979) a adição de $60 \mathrm{~g}$ de xilitol na alimentação diária de pacientes diabéticos não foi capaz de promover aumento significativo na concentração de glicose no sangue. 


\section{LESÕES RENAIS E PARENTERAIS}

O uso do xilitol em nutrição parenteral (dose diária de até $6 \mathrm{~g} / \mathrm{kg}$ de peso corporal) é recomendado por duas razões: 1 . não há reação entre xilitol e aminoácidos, o que facilita a produção de infusões contendo ambos; 2 . os tecidos podem utilizar xilitol sob condições pós-operatórias ou pós-traumáticas (Ylikahri, 1979).

Pacientes em estados pós-operatórios ou pós-traumáticos apresentam uma excreção excessiva dos hormônios do "stress" (cortisol e hormônios do crescimento entre outros), os quais provocam resistência à absorção da insulina e impedem a utilização eficiente da glicose pelo organismo. Conforme relatado por Ylikahri, o tratamento de tais pessoas com xilitol produz apenas aumento limitado dos níveis de glicose e insulina no sangue, beneficiando-lhes a saúde.

\section{ANEMIA HEMOLÍTICA}

A glicose 6-fosfato desidrogenase (G6PDH) é uma enzima citoplasmática de grande importância para a sobrevivência das células, uma vez que é responsável pela manutenção de um nível adequado da coenzima reduzida $\mathrm{NADPH}$.

Em seres humanos, a deficiência da enzima G6PDH configura uma patologia conhecida como anemia hemolítica. Essa deficiência promove a diminuição dos eritrócitos, devido à incapacidade das células de regenerar NADPH, um cofator importante nos processos biológicos oxidativos (Vieira-Neto et al., 1999). Tal patologia, resultante de mutações em diferentes pontos do gene que codifica a enzima, é considerada a enzimopatia mais comum em humanos, pois afeta 400 milhões de pessoas no mundo (Luzzatto, Mehta, 1995). Manifestações clínicas como anemia hemolítica induzida por drogas ou por infecção, favismo, icterícia neonatal e anemia hemolítica congênita crônica estão associadas à deficiência da enzima G6PDH.

O xilitol é um agente terapêutico que pode ser utilizado (dose máxima de $1 \mathrm{mM} / \mathrm{L}$ de sangue) por pessoas com deficiência de G6PDH, uma vez que essa enzima não é requerida para o seu metabolismo. Assim sendo, o xilitol supre a célula de $\mathrm{NADPH}_{2}$ por meio da oxidação da Lxilulose, mantendo a integridade da membrana dos glóbulos vermelhos (Van Eys et al., 1974; Ylikahri, 1979). Um esquema desse processo é apresentado na Figura 2.

\section{OTITE MÉDIA AGUDA}

Otite média aguda, a segunda infecção mais comum em crianças, é causada por bactérias da nasofaringe que penetram no ouvido médio através do tubo de Eustáquio (Erramouspe, Heyneman, 2000).

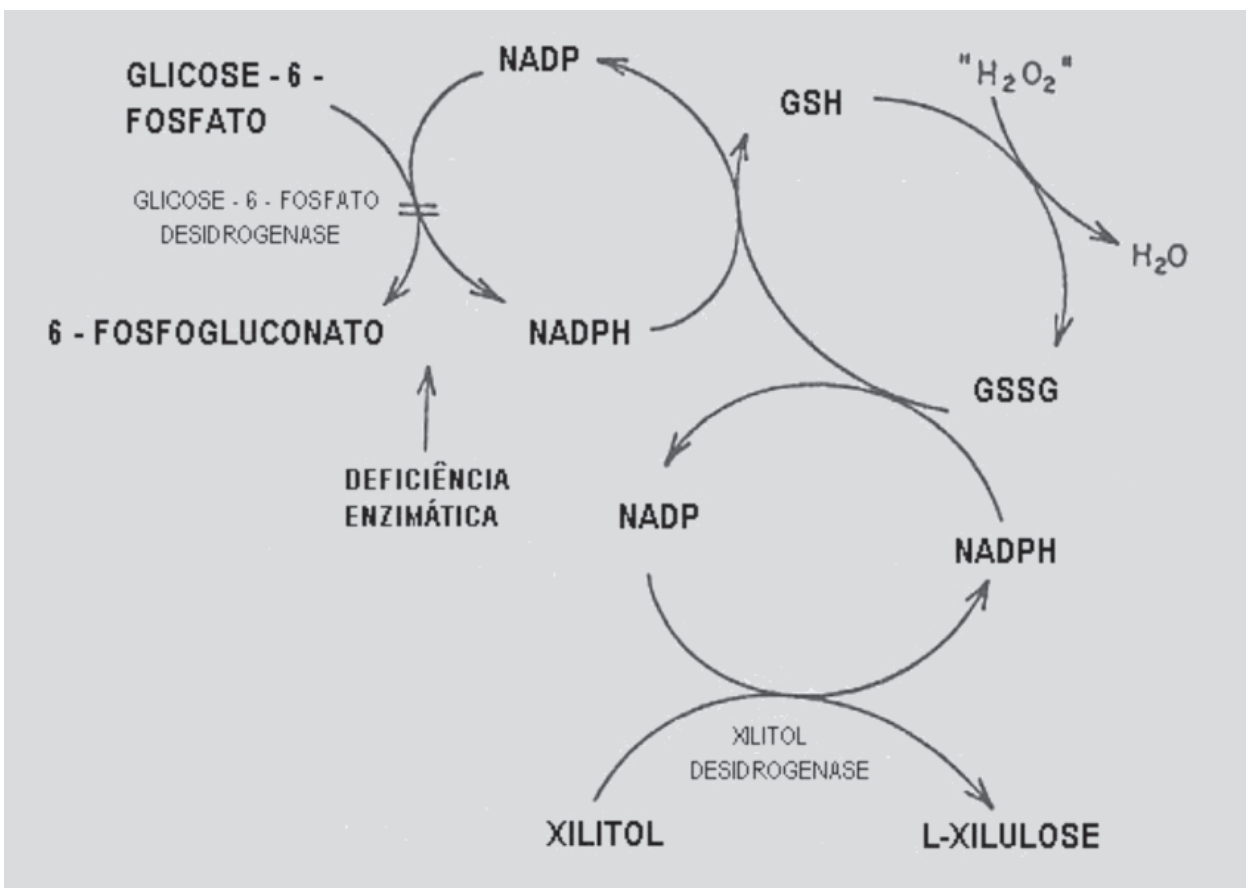

FIGURA 2 - Esquema da utilização de xilitol por pessoas com deficiência da enzima glicose-6-fosfato desidrogenase (Van Eys et al., 1974). 
De acordo com Kontiokari et al. (1995), o xilitol atua na prevenção ou no combate dessa doença, inibindo o crescimento da bactéria Streptococcus pneumoniae, principal causadora de sinusites e infecções no ouvido médio. Segundo Uhari et al. (1996), a dose diária requerida de xilitol capaz de combater a otite média aguda ainda não é conhecida. No entanto, estudos realizados com crianças revelaram que uma dose diária de $8,4 \mathrm{~g}$ de xilitol, dada sob a forma de 2 gomas de mascar (mascadas durante 5 minutos cada), mostrou-se efetiva no combate a esta doença, reduzindo em cerca de $40 \%$ a ocorrência dessa infecção. Também sob a forma de xarope o xilitol foi bem tolerado por crianças e mostrou-se eficaz na prevenção de otite, diminuindo a necessidade de antibióticos (Uhari et al., 1998).

O mecanismo pelo qual o xilitol inibe o crescimento das bactérias $S$. pneumoniae e $S$. mutans foi sugerido por Kontiokari et al. (1995) e por Trahan (2000). Segundo esses autores, o xilitol é transportado pelo sistema frutose fosfotransferase (PTS) para dentro da célula, onde é fosforilado a xilitol-5-fosfato. Como essas espécies bacterianas não possuem as enzimas responsáveis pelo metabolismo do xilitol-5-fosfato formado, ocorre um acúmulo intracelular desse composto. Uma vez acumulado dentro da célula, o xilitol-5-fosfato torna-se tóxico, causando inibição das enzimas glicolíticas e do crescimento das bactérias, cujo tempo de sobrevivência fica reduzido.

Vale a pena destacar que o efeito inibitório do xilitol no crescimento de Pneumococci é totalmente eliminado pela frutose, que é requerida pelo sistema frutose fosfotransferase. Por essa razão, os produtos indicados para prevenir otite média aguda não podem conter mistura de xilitol com frutose (Tapiainen et al., 2001).

\section{OSTEOPOROSE}

A osteoporose é causada pela diminuição da deposição de cálcio nos ossos, que sofrem perda de volume e de propriedades biomecânicas. Essa doença afeta principalmente o fêmur, que se torna mais frágil, quebrando-se com facilidade.

A eficiência do xilitol no tratamento ou na prevenção da osteoporose foi comprovada por Mattila et al. (1998a,b,c; 1999). Em suas pesquisas com animais, esses autores verificaram que o xilitol promove o aumento da massa dos ossos, preserva os minerais neles existentes e evita o enfraquecimento de suas propriedades biomecânicas. Para essas pesquisas, a dieta dos animais foi suplementada com uma quantidade de xilitol que variou de 10 a $20 \%$ na formulação da ração, tendo ficado evidente que, no combate à osteoporose, quanto maior é a dose de xilitol na alimentação, melhores são os resultados alcançados (Figura 3).

Segundo os mesmos autores, o xilitol combate a osteoporose estimulando a absorção de cálcio pelo intestino e facilitando sua passagem do sangue para os ossos. O conteúdo de cálcio nos ossos é, assim, aumentado, diminuindo a necessidade de reabsorção. Durante o metabolismo do xilitol, ocorre um aumento na razão NADH/ NAD, o que leva à supressão do ciclo do ácido cítrico, sendo o NADH usado para produção de energia pela cadeia respiratória. As coenzimas regulam numerosas reações metabólicas e efeitos hormonais e é possível que algumas enzimas em sua forma reduzida desencadeiem reações que preservam o alto nível de cálcio nos ossos. As alterações na razão celular NADH/NAD estão fortemente relacionadas ao processo de calcificação. O aumento da concentração de NADH intensifica o transporte de íons $\mathrm{Ca}^{2+}$ através da membrana celular, ativando o processo de calcificação dos ossos e da cartilagem, e aumentando a síntese de colágeno (Mattila et al., 1996).

Knuuttila et al. (2000) demonstraram que o xilitol é capaz de estimular a síntese de colágeno tanto em ratos saudáveis como em ratos diabéticos. Baseados nesses resultados, e partindo do princípio de que a Diabetes do Tipo I acarreta uma grande degradação de colágeno, esses au-
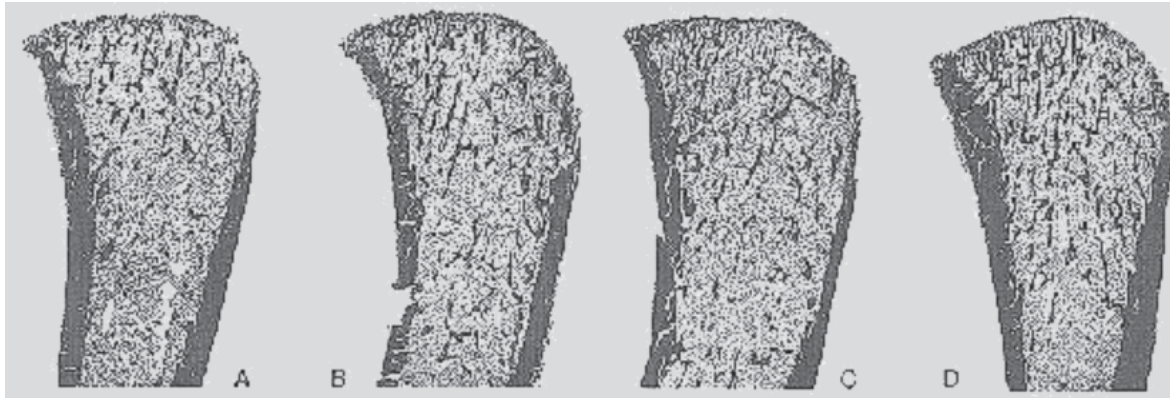

FIGURA 3 - Aumento do volume dos ossos em ratos alimentados por uma dieta suplementada com 5\% (B), 10\% (C) e $20 \%$ de xilitol (D), em comparação ao controle (A), cuja alimentação não continha xilitol (Mattila et al., 1999). 
tores acreditam que a inclusão de xilitol na alimentação de pessoas com esse tipo de diabetes pode estimular a síntese de colágeno, devido ao aumento da razão NADH/NAD, que ocorre durante o metabolismo do xilitol.

Apesar das pesquisas realizadas até agora terem sido conduzidas somente com animais, Mattila et al. (1998b) sugerem que uma dose diária de aproximadamente $40 \mathrm{~g}$ de xilitol na alimentação de pessoas de meia-idade, pode promover um efeito de prevenção à osteoporose, além de ser bem tolerada pelo organismo.

\section{INFECÇÕES RESPIRATÓRIAS}

A superfície interna dos pulmões é revestida por uma fina camada de líquido que contém substâncias antimicrobianas capazes de eliminar as bactérias constantemente aspiradas ou inaladas, prevenindo dessa forma as infecções pulmonares. O aumento da concentração de sais nesse envoltório líquido das células que revestem o interior dos pulmões inibe a atividade antimicrobiana dessas substâncias, fazendo com que as bactérias se espalhem e produzam infecções crônicas. Reduzindo-se a concentração salina do líquido, pode-se aumentar a atividade antimicrobiana e prevenir a infecção.

A eficiência do xilitol no tratamento de doenças respiratórias é atribuída por Zabner et al. (2000) à baixa permeabilidade transepitelial desse edulcorante, que, por isso, não é metabolizado pela maioria das bactérias e pode diminuir a concentração de sais no líquido que reveste a superfície interna dos pulmões. Experimentos realizados por esses autores, a partir de $50 \mu \mathrm{L}$ de uma solução $3 \mathrm{mM}$ de xilitol, demonstraram que as bactérias Staphylococcus aureus e Pseudomonas aeruginosa (principais causadoras de doenças pulmonares) não utilizam xilitol para crescimento, o que faz diminuir a concentração de sais no líquido e aumentar a atividade antibiótica natural dos pulmões. Pode-se dizer, portanto, que o xilitol fortalece o sistema de defesa natural dos pulmões, atrasando ou prevenindo o estabelecimento de infecções bacterianas, entre as quais se inclui a pneumonia.

Pacientes com doenças respiratórias normalmente apresentam congestionamento na mucosa do nariz, dificuldade em respirar e problemas pulmonares, recomendandose nesses casos a irrigação nasal para manter limpas as vias respiratórias e facilitar a respiração. Estudos recentes mostram que o xilitol aplicado em forma de spray nasal reduz a carga bacteriana e aumenta os mecanismos de defesa local (Zabner et al., 2000). Além disso, ele inibe o crescimento de Streptococcus pneumoniae e Haemophillus influenzae, bactérias patogênicas causadoras da sinusite e das infecções respiratórias, e diminui a aderência dessas bactérias às células epiteliais, reduzindo a incidência do processo infeccioso (Tapiainem et al., 2001).

\section{PROCESSOS INFLAMATÓRIOS}

O uso do xilitol como suplemento alimentar $(6$ a $15 \%$ da alimentação) tem demonstrado bons resultados em relação a processos inflamatórios agudos induzidos.

Takahashi e colaboradores (1999) realizaram pesquisas com aves de até 12 dias de idade, alimentando-as por 10 dias com uma dieta que continha $15 \%$ de xilitol. Após esse período, injetaram antígenos nas aves para induzir processos inflamatórios e observaram que o tratamento com xilitol, além de aliviar o retardamento do crescimento e a anorexia provocados pela infecção, ainda preveniu a perda de peso dessas aves, sem afetar ou alterar qualquer outra parte do seu sistema. Em estudos posteriores, esses autores reduziram para $6 \%$ a porcentagem do xilitol na dieta das aves e para apenas 1 dia o período de alimentação antecedente à indução do processo inflamatório. O resultado foi que os mesmos efeitos benéficos foram observados em menos tempo e com um custo menor de tratamento (Takahashi et al., 2000).

Embora pouco numerosas, as pesquisas referentes à aplicação do xilitol na cura ou controle de processos inflamatórios são muito promissoras, pois todas indicam que, com um baixo conteúdo de xilitol na dieta é possível obter-se resultados positivos num curto período de tratamento, sem prejudicar o funcionamento geral do organismo.

\section{PROCESSOS DE OBTENÇÃO DO XILITOL}

O xilitol é um produto intermediário que aparece durante o metabolismo de carboidratos em mamíferos, inclusive no homem (Ylikahri, 1979). Um humano adulto produz de 5 a 15 gramas de xilitol por dia em condições metabólicas normais e a concentração dessa substância no sangue varia de 0,03 a 0,06 mg/100 mL (Pepper, Olinger, 1988). O xilitol é formado no organismo humano como um composto intermediário do ciclo do ácido urônico, sendo consumido para produção de ácido glucurônico, o qual é empregado em processos sintéticos e em reações de destoxificação (Ylikahri, 1979). Na natureza o xilitol pode ser encontrado em muitas frutas, vegetais e cogumelos, porém, em quantidades inferiores a $900 \mathrm{mg} / 100 \mathrm{~g}$, o que torna sua extração um processo antieconômico e impraticável (Parajó et al., 1998b).

Uma alternativa à extração do xilitol diretamente dessas fontes naturais é a sua obtenção pela hidrogenação da D-xilose presente na matéria vegetal, seja por via química, seja por via biotecnológica (Figura 4). 


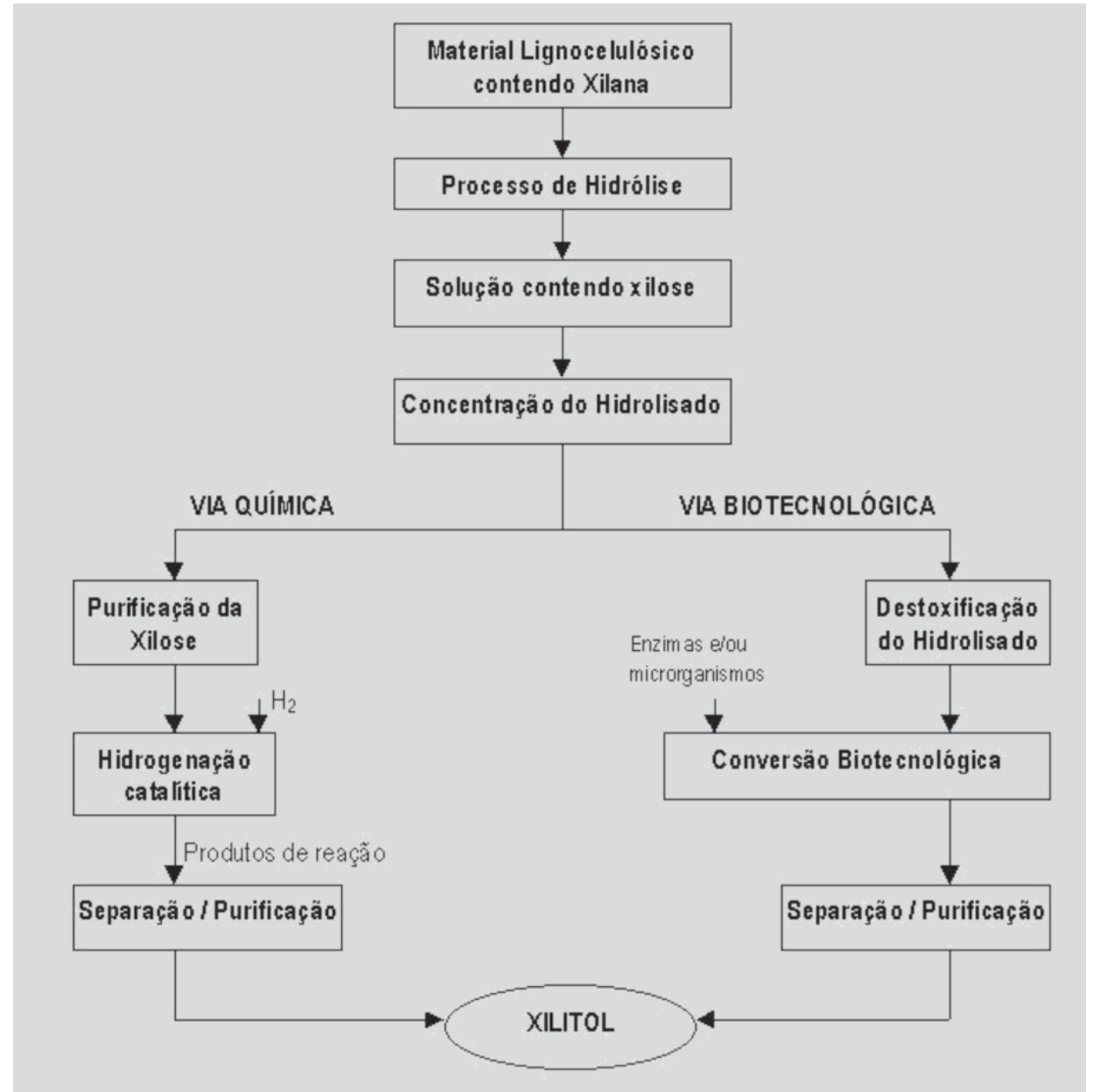

FIGURA 4 - Fluxogramas das tecnologias disponíveis para produção de xilitol.

\section{Processo Químico}

A produção de xilitol por via química em escala industrial teve início em 1975, na Finlândia, com a Finnish Sugar Co. Ltda., em Helsink. Esse processo, que fornece de 50 a $60 \%$ de rendimento de xilitol, é realizado em reatores com elevadas pressões (31-40 atm) e temperaturas $\left(100-130^{\circ} \mathrm{C}\right)$ e tem um tempo de duração de 3 a 5 horas, dependendo das condições de temperatura e pressão empregadas (Jaffe et al.,1974; Melaja, Hämäläinen, 1977). Segundo Melaja e Hämäläinen (1977), esse tempo pode ser reduzido para cerca de 2,5 horas, se os níveis de temperatura e pressão forem superiores a $130{ }^{\circ} \mathrm{C}$ e $40 \mathrm{~atm}$, respectivamente.

O processo químico é o único atualmente utilizado para produção de xilitol em larga escala. Esse processo inclui cinco etapas: 1. Hidrólise ácida do material natural rico em xilana; 2 . Purificação do hidrolisado até obter-se uma solução de xilose pura; 3 . Hidrogenação catalítica da xilose pura a xilitol, com um catalisador (liga de Ni e
$\left.\mathrm{Al}_{2} \mathrm{O}_{3}\right)$; 4. Purificação da solução de xilitol obtida; 5. Cristalização do xilitol (Melaja, Hämäläinen, 1977; Hyvönen et al., 1982).

A purificação da xilose do hidrolisado ácido é a etapa crítica na qual o hidrolisado é submetido a série de operações de troca iônica para remover os subprodutos indesejados (Melaja, Hämäläinen, 1977). Essas pequenas impurezas, particularmente as ligninas, podem envenenar a catálise e paralisar a etapa de redução de forma irreversível (Jaffe et al., 1974).

Conforme relatado por Heikkilä et al. (1992), as etapas do processo químico de produção de xilitol apresentam um custo relativamente alto. A purificação do material de partida é muito complexa, devido à elevada sensibilidade dos catalisadores necessários para a reação. Além disso, a pureza final da solução de xilitol é dependente da separação dos subprodutos originários da reação de redução. Por isso, o custo de produção do xilitol por processo químico é cerca de 10 vezes maior que o da sacarose ou do sorbitol (Parajó et al., 1998a). 


\section{Processo Biotecnológico}

Devido ao elevado custo da produção de xilitol por via química, vários centros de pesquisa no Brasil e no exterior vêm investigando a produção de xilitol por processo biotecnológico, na tentativa de desenvolver uma técnica menos dispendiosa, que seja utilizável em escala industrial.

Os microrganismos mais utilizados nesse processo são as leveduras, cujo cultivo é feito em hidrolisados obtidos de diferentes matérias-primas, tais como palha de arroz, bagaço de cana-de-açúcar e madeira de eucalipto (Mussatto, Roberto, 2001; Alves et al., 1998; Cannetieri et al., 2001).

O processo biotecnológico é, por diversas razões, uma boa alternativa ao método químico convencional, pois além de dispensar a purificação inicial da xilose (convertida em xilitol no próprio hidrolisado), pode utilizar enzimas ou microrganismos específicos, que atuam somente na conversão de xilose em xilitol. Isso leva a maior rendimento do produto e, conseqüentemente, facilita a sua separação. Como os próprios microrganismos catalisam o processo, torna-se desnecessário o uso de catalisador metálico (Parajó et al., 1997). Apesar de todas essas vantagens, a obtenção de xilitol por via biotecnológica está, contudo, associada à capacidade dos microrganismos de sintetizar a enzima xilose redutase (XR). Inicialmente, essa enzima catalisa a redução de xilose a xilitol com a participação dos cofatores NADPH ou NADH (Roseiro et al., 1991). O xilitol, composto relativamente estável, ou é excretado da célula, ou é oxidado a xilulose pela enzima xilitol desidrogenase (XDH), cuja atividade requer os cofatores NAD ou NADP. Em resumo, a produção de xilitol depende de uma elevada atividade da enzima XR ou de uma baixa atividade da enzima XDH, sendo o grau de atividade dessas enzimas o critério utilizado para identificar os melhores produtores (Winkelhausen, Kuzmanova, 1998). Embora as leveduras sejam mais aptas que as bactérias e os fungos para produzir xilitol, é difícil classificar suas várias espécies quanto à capacidade produtiva. Não obstante, há autores que afirmam que as que têm maior potencial pertencem ao gênero Candida (Mayerhoff et al., 1996; Winkelhausen, Kuzmanova, 1998).

Atualmente há muitos estudos sobre a bioconversão de xilose em xilitol por leveduras, a partir de hidrolisados oriundos da fração hemicelulósica da biomassa vegetal. Com vistas à otimização desse processo, diversos pesquisadores tentam estabelecer as melhores condições de cultivo das leveduras, avaliando os efeitos das seguintes variáveis: pH (Roberto et al., 1996; Felipe et al., 1999;
Cannetieri et al., 2001), temperatura (Barbosa et al., 1988; Converti 2001), oxigênio dissolvido (Roberto et al., 1999; Morita, Silva, 2000), concentração inicial de substrato (Felipe et al., 1993; Silva, Roberto, 1999), fonte de nitrogênio (Barbosa et al., 1988; Silva et al., 1994; Roberto et al., 1996), concentração celular inicial (Dominguez et al., 1997; Felipe et al., 1997), presença de outros açúcares (Felipe et al., 1993; Silva et al., 1996) e presença de inibidores (Roberto et al., 1991; Alves et al., 1998; Palmqvist, HahnHägerdal, 2000; Mussatto, Roberto, 2001).

\section{CONCLUSÕES}

Desde a sua aprovação, em 1963, o uso de xilitol em dietas alimentares vem sendo adotado por muitas nações. Também a partir daí, tiveram início muitas pesquisas buscando encontrar aplicações clínicas para esse composto. Hoje, com um grande número de trabalhos já concluídos, sabe-se que o xilitol traz benefícios à saúde humana e pode ser utilizado na área médica para tratamento ou prevenção de doenças. Sua maior aplicação até hoje é na saúde bucal, uma vez que já foi comprovada sua eficiência na redução da incidência de cáries, na estabilização das cáries já formadas e na remineralização dos dentes. O xilitol também tem sido empregado com êxito no tratamento de otites médias agudas e infecções respiratórias, devido ao fato de as espécies bacterianas presentes na nasofaringe, assim como as espécies presentes na flora bucal, não possuírem as enzimas responsáveis pelo metabolismo do xilitol-5fosfato (composto formado pela fosforilação do xilitol dentro da célula). O acúmulo deste composto dentro a célula é tóxico ao microrganismo, afetando seu crescimento e diminuindo seu tempo de sobrevivência. Outra aplicação clínica de grande importância do xilitol é quanto ao seu uso por pessoas diabéticas, o que é possível devido a este não promover aumento significativo na concentração de glicose no sangue.

No que se refere aos processos de produção de xilitol, a via química convencional tem o inconveniente de exigir um grande aporte energético, fato esse que encarece o produto, tornando-o, em relação a outros adoçantes, pouco competitivo para aplicação nas indústrias de alimentos e de fármacos. Por essa razão, diversos centros de pesquisa vêm-se dedicando ao desenvolvimento do processo de produção de xilitol por via biotecnológica, que requer um aporte menor de energia e pode, portanto, tornar o processo economicamente mais viável. Assim, espera-se que, em um futuro próximo, o xilitol seja mais amplamente comercializado no mercado, não somente como adoçante de alimentos, mas também como ingrediente de produtos farmacêuticos. 


\section{ABSTRACT}

\section{Xylitol: a sweetner with benefits for human health}

When utilizing any type of sweetener for the production of drinks and food, the current industries take into account the calories of the sweetener, the possibility of employing it to reduce or to control weight and its similarity to sugar concerning taste. In this regard, a product that has drawn the attention of food and drink manufacturers is xylitol, which stands out among other sweeteners not only because it can be produced by biotechnological process, but also because it has important physicochemical and physiological properties. Owing to these properties, xylitol has much potential for application in the odontological and medical areas, and has been successfully used to combat dental caries and to treat such illnesses as diabetes, disorders in the lipid metabolism and parenteral and renal lesions. Furthermore, xylitol prevents lung infection, otitis and osteoporosis. The incorporation of xylitol into diets brings, therefore, many benefits not only to those who need a controlled food intake, but also to those who care about their own health and physical well-being.

UNITERMS: Xylitol. Dental Caries. Diabetes. Otitis. Osteoporosis. Respiratory Infections.

\section{AGRADECIMENTOS}

Os autores agradecem à FAPESP e ao CNPq, pelo apoio financeiro concedido para execução deste trabalho. Agradecem também a Maria Eunice Machado Coelho pela revisão deste artigo.

\section{REFERÊNCIAS BIBLIOGRÁFICAS}

ALVES, L. A., FELIPE, M. G. A., SILVA, J. B., SILVA, S. S., PRATA, A. M. R. Pre treatment of sugar cane bagasse hemicellulose hydrolysate for xylitol production by Candida guilliermondii. Appl. Biochem. Biotech., v. 7072, p. 89-98, 1998.

ANVISA - Resolução - $\mathrm{RDC} \mathrm{n}^{\circ}$ 3, de 2 de janeiro de 2001 [on line]. Disponível em: http://www.anvisa.gov.br/base/ visadoc/res/res[1727-1-0].doc. Acesso em: 15 out. 2002 (a).

ANVISA - Resolução n³86 de 5 de agosto de 1999 [on line]. Disponível na internet via http://www.anvisa.gov.br/ base/visadoc/res/res[1747-1-0].doc. Acesso em: 15 out. 2002 (b).
BAR, A. Xylitol. In: O'BREIN NABORS, L., GELARDI, R. C., eds. Alternative Sweeteners. 2. ed., New York: Marcel Dekkor Inc., 1991. p.349-379.

BARBOSA, M. F. S., MEDEIROS, M. B., MANCILHA, I. M., SCHNEIDER, H., LEE, H. Screening of yeasts for production of xylitol from D-xylose and some factors which affect xylitol yield in Candida guilliermondii. $J$. Ind. Microbiol., v.3, p.241-251, 1988.

BUSINESS COMMUNICATIONS COMPANY INC. - The global market for polyols [on line]. Disponível em: http:/ /www.the-infoshop.com/study/bc8013_polyols.html. Acesso em: 15/10/2002.

CANNETTIERI, E. V., ALMEIDA e SILVA, J. B., FELIPE, M. G. A. Application of factorial design to the study of xylitol production from Eucalypus hemicelluosic Hydrolysate. Appl. Biochem. Biotechnol., v.94, p.159168, 2001.

CONVERTI, A., PEREGO, P., DOMÍNGUEZ, J. M., SILVA, S. S. Effect of temperature on the microaerophilic metabolism of Pachysolen tannophilus. Enzyme Microb. Technol., v.28, p.339-345, 2001.

CULBERT, S. J., WANG, Y. M., FRITSCHE, H. A., CARR, D., LANTIN, E., van EYS, J. Oral xylitol in American adults. Nutr. Res., v.6, p.913-922, 1986.

DOMINGUEZ, J. M., GONG, C. S., TSAO, G. T. Production of xylitol from D-xylose by Debaryomyces hansenii. Appl. Biochem. Biotechnol., v.63-65, p.117127, 1997.

ERRAMOUSPE, J., HEYNEMAN, C. Treatment and prevention of otitis media. Ann. Pharmacother, v.34, p.1452-1468, 2000.

FELIPE, M. G. A., MANCILHA, I. M., VITOLO, M., ROBERTO, I. C., SILVA, S. S., ROSA, S. A. M. Preparation of xylitol by fermentation of a hydrolysate of hemicellulose obtained from sugarcane bagasse. Arch. Biol. Technol., v.36, n.1, p.103-114, 1993.

FELIPE, M. G. A., VITOLO, M., MANCILHA, I. M., SILVA, S. S. Environmental parameters affecting xylitol production from sugar cane bagasse hemicellulosic hydrolyzate by Candida guilliermondii. J. Ind. Microbiol. Biotechnol., v.18, p.251-254, 1997. 
FELIPE, M. G. A., RODRIGUES, R. C. L. B., VITOLO, M., SILVA, S. S., MANCILHA, I. Toxicity of acetic acid during the production of xylitol by batch fermentation using lignocellulosic hydrolysate at low $\mathrm{pH}$. In: SYMPOSIUM ON BIOTECHNOLOGY FOR FUELS AND CHEMICALS, 21., 1999. Program and Abstracts Colorado:University Park Holiday Inn Fort Collins, 1999. n. 3-12.

GALES, M. A, NGUYEN, T. Sorbitol compared with xylitol in prevention of dental caries. Ann. Pharmacother, v.34, p.98-100, 2000.

HEIKKILÄ, H., NURMI, J., RAKKILA, L., TÖYRYLA, M., KIKKONUMMI. Method for the production of xylitol. Patente US n.5.081.026. 1992.

HYVÖNEN, L., KOIVISTOINEN, P., VOIROL, F. Food technological evaluation of xylitol. Adv. Food Res., v.28, p.373-403, 1982.

ISOKANGAS, P., SÖDERLING, E., PIENIHÄKKINEN, K., ALANEN, P. Occurrence of dental decay in children after maternal consumption of xylitol chewing gum, a follow-up from 0 to 5 years of age. J. Dent. Res., v.79, p.1885-1889, 2000.

JAFFE, G. M., SZKRYBALO, W., WEINERT, P. H. Process for producing xylose. Patent US n 3.784.408. 1974.

KANDELMAN, D. Sugar, alternative sweeteners and meal frequency in relation to caries prevention: new perspectives. Brit. J. Nutr., v.77, p.S121-S128, 1997.

KNUUTTILA, M. L. E., KUOKSA, T. H., SVANBERG, M. J., MATTILA, P. T., KARJALAINEN, K. M., KOLEHMAINEN, E. Effects of dietary xylitol on collagen content and glycosylation in healthy and diabetic rats. Life Sci., v.67, p.283-290, 2000.

KÖNIG, K.G. Diet and oral health. Int. Dent. J., v.50, p.162$174,2000$.

KONTIOKARI, T., UHARI, M., KOSKELA, M. Effect of xylitol on growth of nasopharyngeal bacteria in vitro. Antimicrob. Agents Chemother., v.39, p.1820-1823, 1995.
LUZZATTO, L., MEHTA, A. Glucose-6-phosphate dehydrogenase deficiency. In: SCRIVER, C.R., BEAUDET, A. L., SLY, W.S., VALE, D., eds.The metabolic and molecular bases of inherited disease. 7.ed. New York: McGraw Hill, 1995. cap. 111, p. 3367-3398.

MÄKINEN, K. K., OLAK, J., RUSSAK, S., SAAG, M., SEEDRE, T., VASAR, R., VIHALEMM, T., MIKELSAAR, M., MÄKINEN, P. Polyol-combinant saliva stimulants: a 4-month pilot study in young adults. Acta Odontol. Scand., v.56, p.90-94, 1998.

MÄKINEN, K. K. Can the pentitol-hexitol theory explain the clinical observations made with xylitol? Med. Hypotheses, v.54, p.603-613, 2000.

MÄKINEN, K. K., ISOTUPA, K. P., KIVILOMPO, T., MÄKINEN, P. L., TOIVANEN, J., SÖDERLING, E. Comparison of erythritol and xylitol saliva stimulants in the control of dental plaque and mutans Streptococci. Caries Res., v.35, p.129-135, 2001.

MANZ, U., VANNINEN, E., VOIROL, F. Xylitol - it's properties and use as a sugar substitute in foods. In: F. R. A. SYMPOSIUM ON SUGAR AND SUGAR REPLACEMENTS, 10., London, 1973.

MATTILA, P. T., SVANBERG, M. J., MÄKINEN, K. K., KNUUTTILA, M. L. E., Dietary xylitol, sorbitol and Dmannitol but not erythrytol retard bone resorption in rats. J. Nutr., v.126, p.1865-1870, 1996.

MATTILA, P. T., KNUUTTILA, M. L. E., SVANBERG, M. J. Dietary xylitol supplementation prevents osteoporotic changes in streptozotocin - diabetic rats. Metabolism, v.47, p.578-583, 1998 a.

MATTILA, P. T., SVANBERG, M. J., KNUUTTILA, M. L. E. Dietary xylitol protects against osseal changes in experimental osteoporosis. In: BURCKHARDT, P., ed. Nutritional aspects of osteoporosis. Norwell: A Serono Symposia S. A. Publication, 1998. cap.16, p.157-162.

MATTIlA, P. T., SVANBERG, M. J., PÖKKÄ, P., KNUUTTILA, M. L. E. Dietary xylitol protects against weakening of bone biomechanical properties in ovariectomized rats. J. Nutr., v.128, p.1811-1814, 1998c. 
MATTILA, P., KNUUTTILA, M., KOVANEN, V., SVANBERG, M. Improved bone biomechanical properties in rats after oral Xylitol administration. Calcified Tissue Int., v.64, p.340-344, 1999.

MAYERHOFF, Z. D. V. L., ROBERTO, I. C., SILVA, S. S., FELIPE, M. G. A., MANCILHA, I. M. Seleção de leveduras para produção de xilitol em hidrolisado hemicelulósico de palha de arroz. In: SIMPÓSIO NACIONAL DE FERMENTAÇÕES, 11., 1996. Anais. São Carlos: UFSC, 1996. v. 2, p. 550-555.

MELAJA, A. J., HAMÄLÄINEN, L. Process for making Xylitol. U.S. Patent n. 4.008.285. 18 jun. 1975, publ. 15/ 02/1977.

MORITA, T. A., SILVA, S. S. Inhibition of microbial xylitol production by acetic acid and its relation with fermentative parameters. Appl. Bioch. Biotechnol., v.8486, p.801-808, 2000.

MUSSATTO, S. I., ROBERTO, I. C., Hydrolysate detoxification with activated charcoal for xylitol production by Candida guilliermondii. Biotechnol. Lett., v.23, p.1681-1684, 2001.

PALMQVIST, E., HAHN-HÄGERDAL, B., Fermentation of lignocellulosic hydrolysates. II: Inhibitors and mechanisms of inhibition. Biores. Technol., v.74, p.25-33, 2000.

PARAJÓ, J. C., DOMINGUEZ, H., DOMINGUEZ, J. M. Improved xylitol production with debaryomyces hansenii Y-7426 from raw or detoxified wood hydrolysates. Enzyme Microb. Technol., v.21, p.18-24, 1997.

PARAJÓ, J. C., DOMINGUEZ, H., DOMINGUEZ, J. M. Biotechnological production of xylitol. Part 1: Interest of xylitol and fundamentals of its biosynthesis. Bioresource Technol., v.65, p.191-201, 1998a.

PARAJÓ, J. C., DOMÍNGUEZ, H., DOMÍNGUEZ, J. M. Biotechnological production of xylitol, Part 3: Operation in culture media made from lignocellulose hydrolysates. Bioresource Technol., v.66, p.25-40, 1998 b.

PEPPER, T., OLINGER, P. M. Xylitol in sugar - free confections. Food technol., v.42, n.10, 1988.
ROBERTO, I. C., FELIPE, M. G. A., LACIS, L. C., SILVA, S. S., MANCILHA, I. M. Utilization of sugar cane bagasse hemicellulosic hydrolysate by Candida guilliermondii for xylitol production. Biores. Technol., v.36, p.271-275, 1991.

ROBERTO, I. C., SATO, S., MANCILHA, I. M. Bioconversion of Rice Straw hemicellulose hydrolysate for the production of xylitol: effect of $\mathrm{pH}$ and nitrogen source. Appl. Biochem. Biotechnol., v.57/58, p.339-347, 1996.

ROBERTO, I. C., MANCILHA, I. M., SATO, S. Influence of $\mathrm{K}_{\mathrm{L}}$ a on bioconversion of rice straw hemicellulose hydrolysate to xylitol. Bioprocess. Eng., v.21, p.505-508, 1999.

ROSEIRO, J. C., PEITO, M. A., GIRIO, F. M., AMARALCOLLAÇO, M. T. The effects of the oxygen transfer coefficient and substrate concentration on the xylose fermentation by Debaryomyces hansenii. Arch. Microbiol., v.156, p.484-490, 1991.

SILVA, C. J. S. M., ROBERTO, I. C. Statistical screening method for selection of important variables on xylitol byosynthesis from rice straw hydrolysate by Candida guilliermondii FTI 20037. Biotech. Technol. v.13, p.743747, 1999.

SILVA, S. S., MANCILHA, I. M., QUEIROZ, M. A., FELIPE, M. G. A., ROBERTO, I. C., VITOLO, M. Xylitol Formation by Candida guilliermondii in Media Containing Diferent Nitrogen Sources. J. Bas. Microb. v.34, p.205-208,1994.

SILVA, S. S., ROBERTO, I. C., FELIPE, M. G. A., MANCILHA, I. M. Batch fermentation of xylose for xylitol production in stirred tank bioreactor. Proc. Bioch., v.31, n.6, p.549-553, 1996.

SÖDERLING, E., ISOKANGAS, P., PIENIHÄKKINEN, K., TENOVUO, J. Influence of maternal xylitol consumption on acquisition of mutans Streptococci by Infants. J. Dent. Res., v.79, p.882-887, 2000.

TAKAHASHI, K., ONODERA, K., AKIBA, Y. Effect of dietary xylitol on growth and inflamatory responses in immune stimulated chickens. Brit. Poult. Sci., v.40, p.552-554, 1999. 
TAKAHASHI, K., MASHIKO, T., AKIBA, Y. Effect of dietary concentration of xylitol on growth in male broiler chicks during immunological stress. Poult. Sci., v.79, p.743-747, 2000.

TAPIAINEN T., KONTIOKARI, T., SAMMALKIVI, L., IKÄHEINO, I., KOSKELA, M., UHARI, M. Effect of xylitol on growth of streptococcus pneumoniae in the presence of fructose and sorbitol. Antimicrob. Agents Chemother., v.45, p.166-169, 2001.

TRAHAN, L Microbial mechanisms of action of xylitol in caries prevention. J. Dent. Res., v.79, p.1288, 2000.

UHARI, M., KONTIOKARI, T., KOSKELA, M., NIEMELÄ, M. Xylitol chewing gum in prevention of acute otitis media: double blind randomised trial. Brit. Med. J., v.313, p.1180-1184, 1996.

UHARI, M., KONTIOKARI, T., NIEMELA, M. A Novel use of xylitol sugar in preventing acute otitis media. Pediatrics, v.102, p.879-884, 1998.

VAN EYS, J., WANG, Y. M., CHAN, S., TANPHAICHITR,V. S., KING, S. M. xylitol as a therapeutic agent in glucose-6-phosphate dehydrogenase deficiency. In: SIPPLE, H. L., McNUTT, K. W., eds. Sugars in nutrition. New York: Academic Press, 1974. p.613-631.
VIEIRA-NETO, E., PEREIRA, C. N., FONSECA, A. A. Avaliação do desempenho de rastreamento neonatal de deficiência de glicose-6-fosfato desidrogenase em amostras de sangue em papel filtro. Laes \& Haes, n.119, p.98-104, 1999.

WINKELHAUSEN, E., KUZMANOVA, S. Microbial conversion of D-xylose to xylitol. J. Ferment. Bioeng., v.86, p.1-14, 1998.

YLIKAHRI, R. Metabolic and nutritional aspects of xylitol. Adv. Food Res., v.25, p.159-180, 1979.

ZABNER, J., SEILER, M. P., LAUNSPACH, J. L., KARP, P. H., KEARNEY, W. R., LOOK, D. C., SMITH, J. J., WELSH, M. J. The osmolyte xylitol reduces the salt concentration of airway surface liquid and may enhance bacterial killing. Proc. Nat. Acad. Sci., v.97, p.1161411619, 2000.

Recebido para publicação em 28 de junho de 2002. 